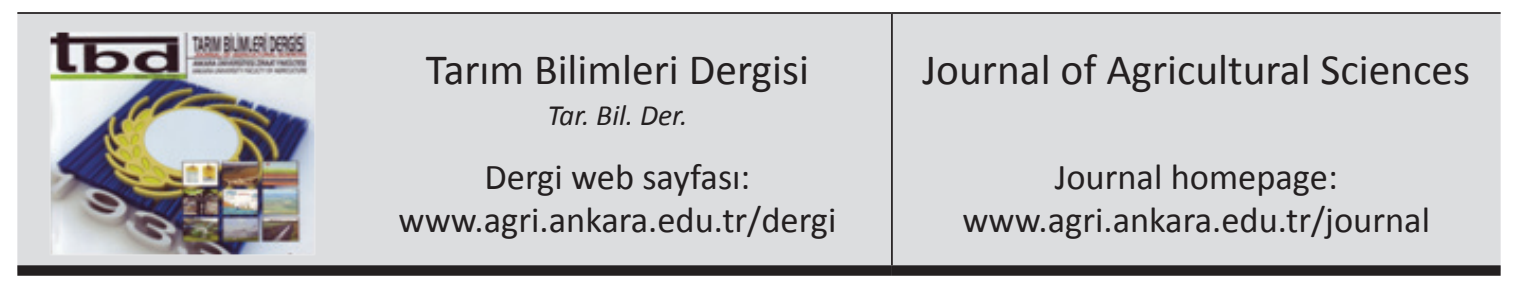

\title{
Tuta absoluta (Meyrick, 1917) (Lepidoptera: Gelechiidae)'nın Farklı Domates Çeşitleri Üzerinde Yaşam Çizelgesi
}

\author{
Demet ÇEKİNa, Bülent YAŞAR ${ }^{\mathrm{b}}$ \\ ${ }^{a}$ University of Natural Resources and Life Sciences, Division of Plant Protection, Department of Crop Sciences, Vienna, AUSTRIA \\ ${ }^{\boldsymbol{b}}$ Süleyman Demirel Üniversitesi, Ziraat Fakültesi, Bitki Koruma Bölümü, Isparta, TÜRKIYE
}

\section{ESER BİLGISI}

Araștırma Makalesi

DOI: 10.1501/Tarimbil_0000001322

Sorumlu Yazar: Bülent YAŞAR, E-posta: bulentyasar99@-̄hotmail.com, Tel: +90 (246) 2114856

Geliş Tarihi: 24 Mart 2014, Düzeltmelerin Gelişi: 13 Haziran 2014, Kabul: 06 Ağustos 2014

\begin{abstract}
ÖZET
Tuta absoluta (Meyrick) (Lepidoptera: Gelechiidae), Akdeniz Bölgesi’nde domatesin önemli zararlılarından birisidir. Bu çalışmada domates güvesinin Newton, Caracas, Torry ve Şimşek domates çeşitleri üzerinde gelişme süresi, ölüm oranı ve yaşam çizelgeleri incelenmiştir. Domates güvesinin toplam gelişme süresi en uzun 24.50 gün ile Caracas çeşidinde saptanmış, bunu sırasıyla Torry, Newton ve Şimşek çeşitleri 23.95, 23.00 ve 22.88 gün ile izlemiştir. Ergin öncesi döneme ait toplam ölüm oranları ise Şimşek, Caracas, Torry ve Newton domates çeşitleri üzerinde sırasıyla \% 73.13, \% 53.79, \% 41.10 ve \% 40.46 olarak saptanmıştır. T. absoluta'nın Torry, Newton, Caracas ve Şimşek domates çeşitlerinde net üreme gücünün $\left(\mathrm{R}_{\mathrm{o}}\right)$ sırasıyla 64.6, 55.8, 47.5, ve 35.8 dişi dişi $1^{-1}$ döl $^{-1}$, kalıtsal üreme kapasitesinin $\left(\mathrm{r}_{\mathrm{m}}\right)$

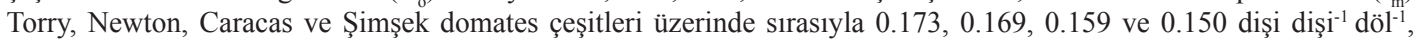
ortalama döl süresinin (To) ise Caracas, Torry, Şimşek ve Newton domates çeşitleri üzerinde sırasıyla 24.3, 24.1 ve 23.9 ve 23.7, gün olduğu belirlenmiştir. Sonuç olarak, Domates güvesinin Şimşek domates çeşidini çalışmada kullanılan diğer çeşitlere oranla daha az tercih ettiği belirlenmiştir.

Anahtar Kelimeler: Domates güvesi; Tuta absoluta; Domates; Yaşam çizelgesi; Isparta
\end{abstract}

\section{The Life Table of Tuta absoluta (Meyrick, 1917) (Lepidoptera: Gelechiidae) on Different Tomato Varieties}

\author{
ARTICLE INFO \\ Research Article \\ Corresponding Author: Bülent YAŞAR, E-mail: bulentyasar99@hotmail.com, Tel: +90 (246) 2114856 \\ Received: 24 March 2014, Received in Revised Form: 13 June 2014, Accepted: 06 August 2014
}

\begin{abstract}
Tuta absoluta (Meyrick) (Lepidoptera: Gelechiidae) is as regarded a serious pest of tomato in the Mediterranean Region of Turkey. The life table parameters, the developmental durations and mortality rates of tomato moth on different tomato varieties, namely Newton, Caracas, Torry and Şimşek were studied. Total developmental duration of tomato moth was the longest in Caracas variety and determined as 24.50 days. It was $23.95,23.00$, and 22.88 days on Torry, Newton,
\end{abstract}


and Şimşek varieties, respectively. Total mortality of immature stages was determined as $73.13 \%, 53.79 \%, 41.10 \%$ and $40.46 \%$ on Şimşek, Caracas, Torry and Newton varieties, respectively. The net reproductive rate (Ro) was 64.6, 55.8, 47.5, and 35.8 females females ${ }^{-1}$ day $^{-1}$ generation on Torry, Newton, Caracas and Şimşek varieties, respectively. The intrinsic rate of increase $\left(r_{m}\right)$ was found as $0.173,0.169,0.159$, and 0.150 females females ${ }^{-1}$ day $^{-1}$ on Torry, Newton, Caracas and Şimşek varieties, respectively. Mean generation time (To) was obtained as 24.3, 24.1, 23.9 and 23.7 days on Caracas, Torry, Şimşek and Newton varieties, respectively. Our results showed that Tomato moth preferred less Şimşek variety than other tomato varieties tested in the present study.

Keywords: Tomato moth; Tuta absoluta; Tomato; Life table; Isparta

(C) Ankara Üniversitesi Ziraat Fakültesi

\section{Giriş}

Güney Amerika kökenli bir zararlı olan Tuta absoluta (Meyrick) (Lepidoptera: Gelechiidae) domatesin en önemli zararlılarından biridir (Barrientos et al 1998; Miranda et al 1998). T. absoluta, Avrupa'da ilk olarak 2006 yılında İspanya'da örtü altında yetiştirilen domateslerde tespit edilmiş, takip eden yetiştirme sezonunda ise İspanya'nın yanında tüm Akdeniz kıyı kesimindeki ülkelere yayılarak ciddi zararlara yol açtığı bildirilmiştir (EPPO 2010).

T. absoluta Türkiye'de ilk olarak 2009 yılı ağustos ayında İzmir ili Urla ilçesinde domates bitkileri üzerinde saptanmıştır. Aynı yıl diğer illerde yapılan surveyler sonucunda zararlının Çanakkale ve Muğla illerinde de görüldüğü bildirilmiştir (Kılıç 2010). Akdeniz Bölgesi'nde ise 2010 yılında Antalya'nın Kumluca ilçesinde bir domates serasında saptanmıştır (Erler et al 2010). Ancak zararlı için uygun ekolojik koşullara sahip olan Türkiye'de hızla yayılmakta olan zararl1, 2010 yılı ağustos ayına kadar Akdeniz ve Ege Bölgelerine tamamen bulaşmış olup daha önce bulunmadığı bölgelere de hızla yayıldığ bildirilmektedir (Erler et al 2010).

Domates bitkisinin tüm toprak üstü organları ile beslenebilen larvası, mücadele edilmediği takdirde bitkide $\% 100$ zarara yol açmaktadır. Zararlı genellikle olgunlaşmamış meyveleri tercih eder ve meyveye genellikle çanak yaprak kısmından giriş yapar. Meyvede galeriler açarak beslenen larva hastalık etmenlerinin gelişmesine de yol açar. Bu şekilde çürümeye başlayan meyvelerin hem işlenme hem de piyasa değerini kaybettiği bildirilmektedir (Estay 2000). T. absoluta'nın en önemli zararı ise bitkinin büyüme noktalarında, çiçeklerinde ve yeni oluşan meyvelerinde beslenmesi yoluyla bitkinin gelişimini hızlı bir şekilde durdurmasıdır. Yumurtalar açıldıktan sonra ilk dönem larvalar, yapraklara, gövdeye veya domates meyvelerine girerek geniş galeriler açar ve bu galerilerin içinde bıraktıkları yoğun siyah pislikler oldukça belirgindir. Ancak uygun iklim koşullarında ana konukçu dışında bazı alternatif bitkilerinde konukçu olabildiği rapor edilmiştir. Örneğin Sicilya'da, İnka eriği (Physalis peruviana L., Solanaceae) serasinda, İtalya'da fasulye (Phaseolus vulgaris L., Fabaceae), Lycium sp. (Solanaceae) ve Malva sp. (Malvaceae) üzerinde saptandığ 1 bildirilmektedir (Caponero 2009; EPPO 2009).

T. absoluta günümüzde Türkiye'de ve dünyada hâlâ yayılma potansiyeline sahiptir. Zararlı ile mücadelede yoğun insektisit kullanılmakta ve bu durum çevre ve insan sağlığı açısından çeşitli olumsuzluklara yol açmaktadır. Lietti et al (2005), yoğun insektisit kullanımının zararlıda dayanıklılığa yol açtığını bildirmektedirler. $T$. absoluta'nın dünyada ve Türkiye'deki domates üretim koşullarında kontrolü için çevre ve insan sağlığına olumsuz etkileri az olan bir mücadele yöntemi tam olarak uygulanamamaktadır. $\mathrm{Bu}$ çalışmada elde edilen sonuçların çevreyle dost, ekonomik ve sürdürülebilir mücadele stratejileri çerçevesinde ileride yapılacak çalışmalara temel oluşturacağ 1 düşünülmektedir. Bu amaçla, Antalya ilinde örtü altında en fazla üretimi yapılan dört domates çeşidi üzerinde $T$. absoluta'nın biyolojisi ve yaşam çizelgesi belirlenmiştir.

\section{Materyal ve Yöntem}

Çalışmanın ana materyalini, Antalya ilinde örtü altında yetiştiricilerin en çok tercih ettiği 
Newton, Caracas, Torry ve Şimşek domates çeşitleri ve Tuta absoluta oluşturmaktadır. Domates güvesinin doğadan toplanan erginlerinin bıraktığı yumurtalardan elde edilen larvaları iklim odalarındaki ergin oluncaya kadar beslenmiş ve onların yumurtaları denemelerde kullanılmıştır. Domates bitkileri $25 \pm 1{ }^{\circ} \mathrm{C}$ sicaklık, \% $65 \pm 5$ orantılı nem ve 16 saat aydınlık 8 saat karanlık koşullara sahip iklim odasında, $25 \mathrm{~cm}$ çapındaki saksılarda geliştirilen bir düzenekle, $15 \mathrm{~cm}$ çapında petri kapları içerisine alınan domates yaprakları üzerinde yürütülmüştür (Şekil 1).

Petri kabının alt ortasına $100 \mathrm{~cm}$ uzunluğunda telden, helezon şeklinde yapılan ve gerektiğinde çekilerek uzayabilen ayak yapıştırıldıktan sonra saksı toprağının üzerine yerleştirilmiş ve bu şekilde bitkiden yaprak koparılmadan zararlının biyolojik dönemleri izlenmiştir. Petri kabının bir kenarında domates dalı girecek şekilde açıklık oluşturulmuş ve dalı petri içerisine yerleştirildikten sonra zararlının kaçışını engellemek amacıyla dalın etrafı küçük sünger parçaları ile sarılmıştır (Şekil 1).

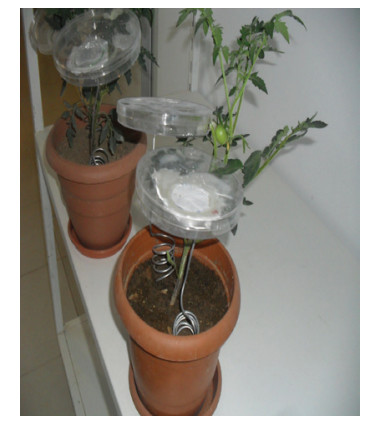

Şekil 1- Petri kapları içine alınan domates bitkisi yaprakları

Figure 1- The tomato leaves placed in petri dish

$\mathrm{Bu}$ düzeneğin tercih edilme nedeni, altında nemli sünger veya pamuk konularak yapılan petri çalışmalarında, bırakılan yaprağın çürümesi veya besinin böcek tarafından kabulünün zorlaşması nedeniyle tamamen doğal ortamdaki konukçusu üzerinde kontrollü olarak beslenmesi amaçlanmıştır. Petrilerin kapaklarında yaklaşı $5 \mathrm{~cm}$, alt kısmında ise yaklaşı $3 \mathrm{~cm}$ çapında daire havalandırma deliği açılmış delik organze tül ile kapatılmıştır.
Deneme, tesadüf parselleri deneme desenine göre dört domates çeşidinde yürütülmüştür. Her çeşitte toplam 50 birey (bir birey tekerrür olarak kabul edilmiştir) kullanılmıştır. Zararlının yumurtaları bir numaralı samur kıl fırça yardımıyla petri kabı içerisindeki domates yaprakları üzerine tek tek bırakılmıştır. Yumurtadan çıkan larvaların gelişmeleri takip edilmiş, her gün aynı saatte gözlenerek yumurta, larva dönemlerinin süreleri ve ölüm oranları saptanmıştır.

Pupa ağırlıkları ikinci günde hassas terazide tartılmıştır. Pupadan çıkan erginler çiftleşmeleri için organze tül ile oluşturulan kafes içerisine bırakılarak beslenmesi için \% $15^{\prime}$ lik şekerli su çözeltisi verilmiştir. Erginler 5 gün kafes içerisinde bir arada tutulduktan sonra ayrilarak tek tek petri kaplarına alınmış ve petri kaplarına pamuğa emdirilmiş \% 15'lik şekerli su bırakılmıştır.

Erginler her gün aynı saatte kontrol edilerek bırakılan yumurtalar firça yardımıyla içerisine kurutma kâğıdı yerleştirilen petri kaplarına tek tek alınmıştır. Yumurtalar Sterobinoküler mikroskop altında her gün kontrol edilerek açılma süreleri ve oranları saptanmıştır. Daha sonra erkek ve dişilerin ömür uzunlukları belirlenmiştir.

Yaşam çizelgelerinin oluşturulmasında, Birch (1948)'ün önerdiği, Howe (1953) ve Watson (1964)'un geliştirmiş olduğu formül kullanılmıştır.

$1=\sum e^{(-r m \cdot x)} l_{x} \cdot m_{x}$

Burada; $l_{x}, \mathrm{x}$ yaştaki bireylerin 1'e göre canlılık oranları; $m_{x}$, günlük dişi başına bırakılan dişi yavru sayısı; e, logaritma taban1; $r_{m}$, kalıtsal üreme yeteneği; $x$, dişi bireylerin gün olarak yaşını ifade etmektedir.

Diğer bir parametre olan net üreme gücü $\mathrm{R}_{\mathrm{o}}$ ise $\mathrm{l}_{\mathrm{x}}$ ve $m_{x}$ değerlerinin günlük çarpımlarının toplanması ile hesaplanmıştır (Birch 1948; Izhevsky \& Orlinsky 1988).

Ortalama döl süresi $\left(T_{o}\right)$;

$R_{o}=\Sigma l_{x} \cdot m_{\mathrm{x}}$

$T_{o}=\operatorname{Ln} R_{o} / r_{m}$ 
Yaşam çizelgelerinden elde edilen $r_{m}$ değerleri Jacknife yöntemi kullanılarak yeni değerler elde edilmiştir. Sonuçlar ise Duncan testine göre karşılaştırılmıştır. Jacknife formülü (Meyer et al 1986; Sokal \& Rohlf 1995);

$J r_{m i}=\left(r_{m i} n-r_{m i j}(n-1)\right)$

Çalışmada elde edilen tüm değerler Varyans Analizi (ANOVA) tekniği ile değerlendirilmiştir. Grup ortalamaları arasındaki farklılıkların karşılaştırılmasındaçoklukarşılaştırmayöntemlerinden DUNCAN testi kullanılmıştır $(\mathrm{P}=0.05)$.

\section{Bulgular ve Tartışma}

Dört domates çeşidi üzerinde Tuta absoluta'nın ergin öncesi biyolojik dönemlerinin gelişme süreleri ile ilgili elde edilmiş veriler Çizelge 1 'de verilmiştir.

Biyolojik dönemler ayrı ayrı incelendiğinde, $T$. absoluta'nın yumurta açılma süresi en uzun Torry ve Caracas çeşitlerinde sırasıyla 6.58 ve 6.44 gün bulunmuş, Newton ve Şimşek çeşitlerinde ise sırasıyla 5.52 ve 5.28 gün olarak saptanmıştır. Caracas ve Torry çeşitleri arasındaki farkın önemsiz, fakat bu çeşitler ile Şimşek çeşidi arasındaki farkın ise önemli olduğu görülmüştür $(\mathrm{P}<0.05)$. Newton çeşidiyle beslenen Domates güvesinde yumurta açılma süresinin diğer çeşitlerden farkının önemsiz olduğu saptanmıştır. EPPO (2005), Domates güvesinde yumurtanın açılma süresinin 4-5 gün olduğunu belirtmekte olup bu sonuç, çalışmada Şimşek ve Newton çeşitlerinden elde edilen değerler ile benzerlik göstermektedir. Elde edilen sonuçlara göre domates çeşitlerinin, yumurta açılma süreleri üzerine etkili olduğunu söylemek mümkündür (Çizelge 1).

Tuta absoluta'nın I. larva döneminin en uzun gelişme süresi Caracas çeşidinde 3.56, en kısa ise 3.11 günde Newton çeşidinde tamamlamıştır (Çizelge 1). Torry ve Şimşek çeşitlerinde ise I. larva sürelerinin sirasıyla 3.25 ve 3.18 günde tamamlanmıştır. İstatistiksel analiz sonucunda Domates güvesinin I. dönem larva süreleri üzerine domates çeşitlerinin etkisinin önemli olmadığı saptanmıştır. Benzer şekilde, II. dönem larva süresine çeşitlerin etkisi de önemsiz bulunmuştur ( $\mathrm{P}>0.05)$ (Çizelge 1).

Tuta absoluta'nın, III. dönem larvalarının gelişme süresi en kısa Newton çeşidinde (2.53 gün), en uzun Şimşek çeşidinde (3.24 gün) saptanmıştır. Newton çeşidinin Şimşek çeşidi ile arasındaki fark önemli $(\mathrm{P}<0.05)$ diğerleri ile arasındaki fark ise önemsiz bulunmuştur ( $\mathrm{P}>0.05)$ (Çizelge 1).

Tuta absoluta'nın IV. dönem larvalarının en uzun gelişme süresi Caracas (3.13 gün) ve Newton (3.00 gün) çeşitlerinde saptanmıştır. En kısa gelişme süresi ise Şimşek (2.71 gün) ve Torry (2.95 gün) çeşitlerinde belirlenmiştir. Newton ve Caracas çeşitlerinin Şimşek çeşidi ile aralarındaki fark önemli bulunmasına karşın Torry çeşidi ile farkının da önemli olmadığı görülmüştür ( $\mathrm{P}>0.05)$ (Çizelge 1).

Çalışmada toplam larva gelişme süresi en uzun 12.76 gün ile Caracas çeşidinde, en kısa 11.75 gün ile Newton çeşidinde bulunmuş olup, Torry ve Şimşek çeşitlerinde sırasılyla; 11.85 ve 12.13 gün olarak saptanmıştır. Pereyra \& Sánchez (2006) tarafindan

\section{Çizelge 1- Dört domates çeşidi ile beslenen Tuta absoluta'nın ergin öncesi dönemlerinin gelişme süreleri}

Table 1- The development durations of Tuta absoluta feeding on four tomato varieties

\begin{tabular}{lcccc}
\hline \multirow{2}{*}{$\begin{array}{l}\text { Gelişme } \\
\text { dönemleri }\end{array}$} & Newton & Caracas & Torry & Şimşek \\
\cline { 2 - 5 } Yumurta & $5.52 \pm 0.87 \mathrm{ab}^{*}$ & $6.44 \pm 0.42 \mathrm{a}$ & $6.58 \pm 0.76 \mathrm{a}$ & $5.28 \pm 0.12 \mathrm{~b}$ \\
\hline I. Larva & $3.11 \pm 0.16 \mathrm{~b}$ & $3.56 \pm 0.12 \mathrm{a}$ & $3.25 \pm 0.16 \mathrm{ab}$ & $3.18 \pm 0.15 \mathrm{ab}$ \\
\hline II. Larva & $3.11 \pm 0.16 \mathrm{a}$ & $3.13 \pm 0.20 \mathrm{a}$ & $3.00 \pm 0.17 \mathrm{a}$ & $3.00 \pm 0.22 \mathrm{a}$ \\
\hline III. Larva & $2.53 \pm 0.11 \mathrm{~b}$ & $2.94 \pm 0.14 \mathrm{ab}$ & $2.75 \pm 0.17 \mathrm{ab}$ & $3.24 \pm 0.18 \mathrm{a}$ \\
\hline IV. Larva & $3.00 \pm 0.24 \mathrm{a}$ & $3.13 \pm 0.23 \mathrm{a}$ & $2.95 \pm 0.18 \mathrm{ab}$ & $2.71 \pm 0.22 \mathrm{~b}$ \\
\hline Pupa & $5.47 \pm 0.17 \mathrm{a}$ & $5.31 \pm 0.17 \mathrm{a}$ & $5.45 \pm 0.18 \mathrm{a}$ & $5.47 \pm 0.19 \mathrm{a}$ \\
\hline Toplam & $23.00 \pm 0.20 \mathrm{ab}$ & $24.50 \pm 0.35 \mathrm{a}$ & $23.95 \pm 0.27$ ab & $22.88 \pm 0.45 \mathrm{~b}$ \\
\hline *, aynı satırda aynı harf ile gösterilen ortalamalar istatistiksel olarak birbirinden farklı değildir $(\mathrm{P} \leq 0.05)$
\end{tabular}


benzer koşullarda T.absoluta'nın domates ve patates bitkileri üzerinde yaşam çizelgeleri oluşturulmuş, toplam larva gelişme süresi 12.14 gün olarak belirlenmiştir. $\mathrm{Bu}$ sonucun çalışmadan elde edilen sonuçlar ile uyumlu olduğu görülmektedir.

Dört domates çeşidi üzerinde beslenen $T$. absoluta'nın pupa süreleri arasındaki farkın da önemli olmadığı görülmüştür ( $\mathrm{P}>0.05$ ) (Çizelge 1).

T. absoluta'nın toplam gelişme süresi, en uzun Caracas (24.50 gün), en kisa Şimşek (22.88 gün) çeşidinde olduğu belirlenmiş ve aralarındaki fark önemli bulunmuştur $(\mathrm{P}<0.05)$ (Çizelge 1).

Farklı domates çeşitleri üzerinde beslenen $T$. absoluta'nın ergin öncesi dönemlerinde görülen ölüm oranları incelendiğinde, yumurta döneminde ölüm oranı en fazla Şimşek, en az Caracas çeşidinde gözlenmiştir. Larva dönemlerindeki ölüm oranları, domates çeşitlerinde tüm dönemler için farklı değerler almıştır. En fazla ölüm, IV. larva döneminde, en az ölüm ise I. larva döneminde görülmüştür. $\mathrm{Bu}$ sonuçlara göre en yüksek ölüm oranları I. larva döneminde Newton ve Torry, II. larva döneminde Caracas, III. larva döneminde Torry ve Şimşek, IV. larva döneminde Şimşek ve Caracas çeşitlerinde, pupa döneminde ise Caracas çeşidinde olmuştur (Çizelge 2).
Denemede kullanılan çeşitler arasında ergin öncesi dönemlerdeki en yüksek ölüm oranı \% 73.13 ile Şimşek çeşidinde bulunmuştur. Bu durum, yumurta ve IV. larva dönemlerinde meydana gelen yüksek ölümlerden kaynaklanmıştır. En düşük ölüm oranı Newton çeşidinde \% 40.66 olarak saptanmış olup, Caracas ve Torry çeşitlerinde sırasıyla $\% 53.79$ ve $\% 41.10$ oranında bulunmuştur.

Farklı domates çeşitlerinde gelişmesini tamamlayarak ergin olan dişi ve erkeklerde elde edilen ömür değerleri Çizelge 3'te verilmiştir.

Dişi bireylerinin yaşam süresi, domates çeşitlerine göre farklılık göstermiş, ancak aralarındaki farkın önemli olmadığı bulunmuştur Erkek bireylerin ömürleri karşılaştırıldığında, Newton ve Caracas çeşitleri arasındaki fark önemsiz, diğerleri ile aralarındaki fark ise önemli Torry ve Şimşek çeşitleri arasındaki fark önemsiz bulunmuştur ( $\mathrm{P}>0.05)$ (Çizelge 3).

Fernandez \& Montagne (1990), yaptıkları çalışmada laboratuvar koşullarında, erkek kelebeklerin, dişi kelebeklerden daha uzun yaşadığını, çiftleşmiş erkeklerin 26 gün çiftleşmemiş erkeklerin ise 36 gün yaşadığını bildirmektedir. Bu çalışmada Newton ve Caracas çeşitleriyle beslenen çiftleşmiş

Çizelge 2- Dört domates çeşidinde beslenen Tuta absoluta'nın ergin öncesi dönemlerinde ölüm oranları (\%) Table 2- The mortality rates (\%) of the immature stages of Tuta absoluta feeding on four tomato varieties

\begin{tabular}{|c|c|c|c|c|c|c|c|c|c|c|c|c|c|}
\hline \multirow{2}{*}{ Çeşitler } & \multirow[b]{2}{*}{$n$} & \multicolumn{2}{|c|}{ Yumurta } & \multicolumn{7}{|c|}{ Larva } & \multirow[b]{2}{*}{$n$} & \multirow[t]{2}{*}{ Pupa } & \multirow{2}{*}{ Toplam } \\
\hline & & & $n$ & $I$ & $n$ & $I I$ & $n$ & $I I I$ & $n$ & $I V$ & & & \\
\hline Newton & 100 & 14.66 & 50 & 4 & 48 & 2.08 & 47 & 4.25 & 45 & 6.66 & 42 & 9.52 & 40.66 \\
\hline Caracas & 100 & 7.79 & 50 & 2 & 49 & 4.08 & 48 & 2.08 & 47 & 17.02 & 39 & 23.07 & 53.79 \\
\hline Torry & 100 & 9.10 & 50 & 4 & 48 & 2.08 & 47 & 6.38 & 44 & 9.09 & 40 & 10.00 & 41.10 \\
\hline Şimşek & 100 & 37.13 & 50 & 0 & 50 & 2.00 & 49 & 6.12 & 46 & 21.73 & 36 & 5.55 & 73.13 \\
\hline
\end{tabular}

\section{Çizelge 3- Dört domates çeşidinde beslenen Tuta absoluta'nın ergin ömrü ve pupa ağırlıkları}

Table 3- The longivity and pupae weights of Tuta absoluta feeding on four different tomato varieties

\begin{tabular}{lccc}
\hline Çeşitler & + & \multicolumn{1}{c}{ Pupa ă̆ırlı̆̆ $(\mathrm{mg})$} \\
\hline Newton & $30.42 \pm 0.9 \mathrm{a}$ & $25.62 \pm 0.6 \mathrm{a}$ & $3.52 \pm 0.04 \mathrm{a}$ \\
\hline Caracas & $28.75 \pm 0.8 \mathrm{a}$ & $26.09 \pm 0.8 \mathrm{a}$ & $3.20 \pm 0.07 \mathrm{ab}$ \\
\hline Torry & $29.10 \pm 0.6 \mathrm{a}$ & $21.50 \pm 0.4 \mathrm{~b}$ & $2.59 \pm 0.01 \mathrm{~b}$ \\
\hline Şimşek & $29.18 \pm 1.2 \mathrm{a}$ & $21.67 \pm 0.7 \mathrm{~b}$ & $3.19 \pm 0.01 \mathrm{ab}$ \\
\hline *, aynı sütunda aynı harfi içeren ortalamalar istatistiksel olarak birbirinden farklı değildir $(\mathrm{P} \leq 0.05)$
\end{tabular}

Tarım Bilimleri Dergisi - Journal of Agricultural Sciences 21 (2015) 199-206 
erkeklerin ömürleri, adı geçen araştırıcıların sonuçlarıyla benzerlik göstermektedir. Çiftleşmiş erkeklerin ömrü Torry ve Şimşek çeşitlerinde daha az olmuştur. Adı geçen araştırmacıların çiftleşmiş dişilerde 23, çiftleşmemiş dişiler ise 28 gün olarak buldukları sonuç, bu çalışmada tüm domates çeşitlerinden elde edilen üzerinde beslenen dişilerin ömürleri ile benzerlik göstermektedir.

Farklı domates çeşitleri üzerinde beslenen T. absoluta'nın larvaları, pupa olduktan bir gün sonra tartılmıştır. Pupaların ağırlıkları Çizelge 3'te verilmiştir. Pupa ağırlığı, en fazla Newton çeşidinde, en az Torry çeşidinde bulunmuştur. Caracas çeşidi ile Newton ve Şimşek çeşitleri arasındaki fark önemsiz, Torry çeşidi arasındaki fark önemli bulunmuştur ( $\mathrm{P}>0.05)$. Pereyra \& Sánchez (2006), yaptıkları çalışmada çeşit ismini belirtmeden domates üzerinde beslenen T. absoluta'nın ortalama pupa ağırlığının $3.44 \mathrm{mg}$ olduğunu bildirmiştir. $\mathrm{Bu}$ veri Newton çeşidinden elde edilen değer ile benzerlik göstermektedir.

T. absoluta'nın dört domates çeşidi ile beslendikten sonra bıraktıkları günlük ve toplam yumurta sayıları Çizelge 4'te verilmiştir. Ortalama günlük yumurta sayısı en fazla Torry çeşidinde bulunmuştur. Newton ve Torry çeşitleri arasındaki fark önemsiz bulunurken, bu çeşitler ile Caracas ve Şimşek çeşitleri arasındaki farkın önemli olduğu belirlenmiştir $(\mathrm{P}<0.05)$. Bir dişinin ortalama günlük ve ömrü boyunca toplam biraktığ1 yumurta sayıları domates çeşidine bağlı olarak belirgin bir şekilde farklılık göstermiştir. Newton ve Torry çeşitleri arasındaki fark önemsiz, bu çeşitler ile Caracas ve Şimşek çeşitleri arasındaki fark önemli bulunmuştur $(\mathrm{P}<0.05)$. Ovipozisyon süreleri genelde çok kısa olan bu türün dişilerinin en uzun 7.37 (5-13) ile Newton çeşidi üzerinde olmuş ve diğer çeşitlerle arasındaki fark istatistikî olarak önemli bulunmuştur $(\mathrm{P}<0.05)$.

Pereyra \& Sánchez (2006), T. absoluta dişilerinin domates yaprakları üzerinde ortalama 132.7 adet yumurta bıraktığını bildirmektedir. Torres et al (2001), dişi üretkenliğinin 60-120 adet yumurta arasında değişebildiğini, Fernandez \& Montagne (1990), dişilerin ömrü boyunca en fazla 260 adet yumurta bırakabileceğini bildirmişlerdir. Bu sayının çalışmada elde edilen değerlerin çok üzerinde olduğu görülmektedir. Bunun kullanılan domates çeşidinin farklı olmasından çok, bu çalışmada asıl amacın yaşam çizelgesi oluşturma olması nedeniyle, dişilerin sadece bir kez çiftleştirilmelerinden kaynaklanmış olabileceği düşünülmektedir.

Venezuela'da yürütülen bir laboratuvar çalışmasında, dişilerin 20 günden fazla yumurta bırakabildiği, yumurtaların \% 72.3'ünün ilk 5 günde, \% 90'ının ise ilk 10 günde bırakıldığı ayrıca, 94 yumurtanın \% 96.8'inin sabah $06^{00}-09^{00}$ saatleri arasında açıldığı bildirilmiştir (Fernandez \& Montagne 1990). Farklı domates çeşitlerinin, üzerinde beslenen domates güvelerinden elde edilen verilerden yararlanılarak, her domates çeşidi için ayrı ayrı yaşam çizelgeleri hesaplanmış ve sonuçlar Çizelge 5'de verilmiştir. Ayrıca tüm domates çeşitlerine ait yaşam çizelgesi eğrileri Şekil 2'de gösterilmiştir.

Çizelge 5'de görüldüğü gibi, "net üreme gücü (Ro)" Torry çeşidinde 64.6 dişi dişis ${ }^{-1}$ döl $^{-1}$ ile en yüksek saptanmış, Newton, Caracas ve Şimşek çeşitlerinde sırasıyla $55.8,47.5$ ve 35.8 dişi dişi ${ }^{-1}$ döl ${ }^{-1}$ olarak bulunmuştur. Pereyra \& Sánchez (2006), Domates güvesi dişilerinin Ro değerini, domateste 48.9 ve patates üzerinde 14.4 dişi dişi ${ }^{-1}$ döl $\mathrm{l}^{-1}$ olduğunu bildirmektedir.

Çizelge 4- Tuta absoluta dişilerinin dört domates çeşidi üzerindeki ovipozisyon süreleri ve yumurta sayıları Table 4- The oviposition durations and laid eggs number of Tuta absoluta females on four tomato varieties

\begin{tabular}{cccccc}
\hline \multicolumn{2}{c}{ Bırakılan yumurta sayıs } & \multicolumn{2}{c}{ Ovipozisyon süresi } \\
\hline Çeşitler & Günlük & Toplam & Min-Max & Ortalama & Min-Max \\
\hline Newton & $8.90 \pm 0.68 \mathrm{a}^{*}$ & $108.84 \pm 8.84 \mathrm{a}$ & $50-194$ & $7.37 \pm 0.48 \mathrm{a}$ & $5-13$ \\
\hline Caracas & $7.76 \pm 0.73 \mathrm{~b}$ & $80.31 \pm 7.50 \mathrm{~b}$ & $36-139$ & $5.81 \pm 0.36 \mathrm{bc}$ & $4-8$ \\
\hline Torry & $9.48 \pm 0.46 \mathrm{a}$ & $109.90 \pm 5.45 \mathrm{a}$ & $56-144$ & $6.25 \pm 039 \mathrm{~b}$ & $3-10$ \\
\hline Şimşek & $5.40 \pm 0.72 \mathrm{c}$ & $67.53 \pm 11.7 \mathrm{c}$ & $8-131$ & $5.44 \pm 0.65 \mathrm{c}$ & $3-11$ \\
\hline
\end{tabular}

*, aynı sütunda aynı harfi içeren ortalamalar istatistiksel olarak birbirinden farklı değildir $(\mathrm{P} \leq 0.05)$ 
Popülâsyon artışını gösteren en önemli parametrelerden biri olan "kalıtsal üreme yeteneği $\left(r_{m}\right)$ " en yüksek olarak 0.173 dişi dişi ${ }^{-1}$ gün ${ }^{-1}$ ile Torry çeşidinde, en düşük ise 0.150 dişi dişi $^{-1}$ gün $^{-1}$ ile Şimşek çeşidinde bulunmuştur. Caracas ve Newton çeşitlerinde ise sırayla 0.159 ve 0.169 dişi dişisi ${ }^{-1}$ gün${ }^{1}$ olmuştur. Elde edilen sonuçlar, Jack-knife yöntemi ile karşılaştırılmış ve Caracas ile Şimşek çeşidinin arasındaki farkın önemsiz olduğu ayrıca, Torry ve Newton çeşitleri ile arasındaki farkın da önemli olduğu belirlenmiştir $(\mathrm{P}<0.05)$.

Pereyra \& Sánchez (2006), T. absoluta ile yaptıkları çalışmada, çeşit ismi belirtmeksizin kalıtsal üreme yeteneğinin $\left(\mathrm{r}_{\mathrm{m}}\right)$, domates üzerinde 0.14 dişi dişi $^{-1}$ gün $^{-1}$ olduğunu bildirmektedirler. $\mathrm{Bu}$ çalışmada kullanılan tüm çeşitlerden elde edilen kalıtsal üreme yeteneği değerleri, araştırıcıların kullandığı domates çeşidinden daha yüksek olmuştur. Ortalama döl süresi $\left(T_{0}\right)$, çalışmada kullanılan tüm domates çeşitlerinde hemen hemen birbirine yakın bulunmuştur. Pereyra \& Sánchez (2006), çeşit belirtmeksizin domates üzerinde yaptıkları yaşam çizelgeleri çalışmasında ortalama döl süresinin $\left(\mathrm{T}_{0}\right)$, 27.98 gün olduğunu bildirmektedir. $\mathrm{Bu}$ çalışma sonuçları ile arasındaki farkın çeşit farklılığından kaynaklanabileceği düşünülmektedir.

\section{Sonuçlar}

Sonuç olarak, larvaları Şimşek domates çeşidi üzerinde beslenen Domates güvesi dişilerinin net üreme gücü $\left(\mathrm{R}_{0}\right)$ ve kalıtsal üreme yeteneğinin $\left(\mathrm{r}_{\mathrm{m}}\right)$ diğer çeşitler üzerinde beslenenlere göre daha düşük

\section{Çizelge 5- Tuta absoluta'nın dört domates çeşidi üzerindeki yaşam çizelgesi parametreleri}

Table 5- The life table parameters of Tuta absoluta on four tomato varieties

\begin{tabular}{lccc}
\hline Çeşitler & $R_{0}\left(\right.$ dişi dişi $^{-1}$ d̈̈l $\left.^{-1}\right)$ & $r_{m}\left(\right.$ dişi dişi $^{-1}$ gün $\left.^{-1}\right)$ & $T_{0}($ gün $)$ \\
\hline Newton & 55.8 & $0.169 \mathrm{~b} *$ & 23.7 \\
Caracas & 47.5 & $0.159 \mathrm{c}$ & 24.3 \\
Torry & 64.6 & $0.173 \mathrm{a}$ & 24.1 \\
Şimşek & 35.8 & $0.150 \mathrm{c}$ & 23.9 \\
\hline
\end{tabular}

*, aynı sütunda aynı harfi içeren ortalamalar istatistiksel olarak birbirinden farklı değildir $(\mathrm{P} \leq 0.05)$

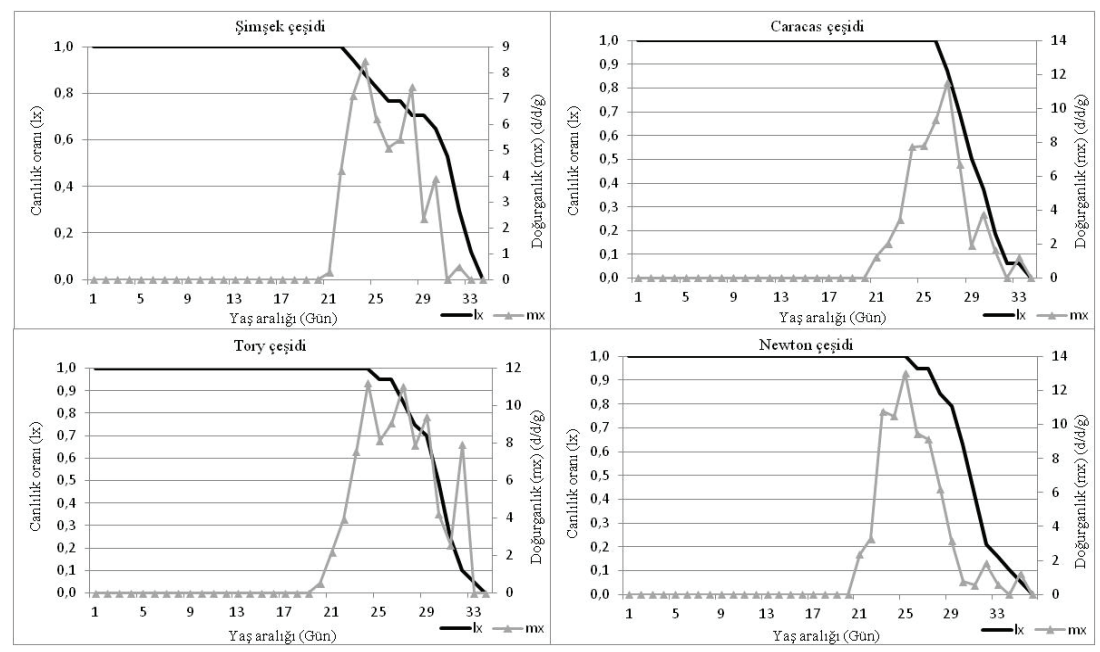

Şekil 2- Dört domates çeşidi üzerinde beslenen Tuta absoluta'nın yaşam ve doğurganlık eğrileri

Figure 2- The life and fecundity curves of Tuta absoluta feeding on four tomato varieties 
bulunmuştur. Ayrıca bu çeşit üzerinde beslenen larvalardan elde edilen ergin dişiler diğer çeşitlerde beslenenlere göre daha az yumurta birakmıştır. $\mathrm{Bu}$ sonuç da bu çeşidin çoğalma açısından domates güvesi için uygun bir çeşit olmadığını göstermektedir. Ayrıca Şimşek çeşidi üzerinde beslenen larvalarda ölüm oranı diğer çeşitlerle beslenenlerden daha yüksek olmuştur. Bunlara ek olarak Şimşek çeşidi üzerinde beslenen larvalardan elde edilen dişilerin bıraktıkları yumurtaların açılma oranı diğer çeşitlerden daha düşük olmuş ve yumurta açılma süresinin de daha uzun olması böceğin üreme kapasitesini azaltmıştır. Bütün bu sonuçlar göz önüne alındığında, Şimşek domates çeşidinin, çalışmada kullanılan diğer çeşitlerle karşılaştırıldığında $T$. absoluta'nın üreme ve yaşamını sürdürebilmesi için olumsuz özelliklere sahip olduğu bulunmuştur. Bundan dolayı bu çeşidin üreticiler tarafindan dikiminin tercih edilmesinin Domates güvesine karşı mücadelede önemli bir kültürel önlem olabileceği kanısına varılmıştır.

\section{Teşekkür}

3511-YL1-13 nolu proje çerçevesinde bu çalışmaya maddi destek sağlayan Süleyman Demirel Üniversitesi Rektörlüğü, Bilimsel Araştırma Projeleri Koordinasyon Birimi Başkanlığına teşekkür ederiz.

\section{Kaynaklar}

Barrientos R, Apablaza J, Norero A \& Estay P (1998). Temperatura Base y constante termica de desarrollo de la polilla del tomate, Tuta absoluta (Lepidoptera: Gelechiidae). Ciencia e Investigacion Agraria 25(3): 133-137

Birch L C (1948). The instrinsic rate of naturel increase on an insect population. Journal of Animal Ecology 17: $15-26$

Caponero A (2009). Solanacee, Rischio in serre. resta alta l'attenzione alla tignola del pomodoro nelle colture protette. Colture Protette 10: 96-97

EPPO (2005). Tuta absoluta. Data sheets on quarantine pests. European and Mediterranean Plant Protection Organization Bulletin 35: 434-435 (Access date: 22.04.2010)

EPPO (2009). Reporting service-Pest \& Diseases. No 8, Paris, 2009-08-01 (Access date: 02.02.2010)
EPPO (2010). Reporting service-Pest \& Diseases. No 1, Paris, 2010-01-01 (Access date: 08.02.2010)

Erler F, Can M, Erdoğan M, Ateş A Ö \& Pradier T (2010). New record of Tuta absoluta (Meyrick) (Lepidoptera: Gelechiidae) on Greenhouse-grown tomato in southwestern Turkey (Antalya). Journal Entomology Sciences 45(4): 1-2

Estay P (2000). Polilla del tomate Tuta absoluta (Meyrick) [www document] URL http://alerce.inia.cl/ docs/_Informativos/ Informativo09.pdf (Access date: 02.02.2010)

Fernandez S \& Montagne A (1990). Biologica del minador del tomate, Scrobipalpula absoluta (Meyrick). Bollettin Entomologia Venezuela 5(12): 89-99

Howe R W (1953). The rapid determination of the intrinsic of increase of an insect population. Annals of Applied Biology 40: 134-151

Izhevsky S S \& Orlinsky A D (1988). Life history of the importes Scymnus (Nephus) reunioni (Col.: Coccinellidae) predator of mealbugs. Entomophaga 33(1): 101-114

Kilıç T (2010). First record of Tuta absoluta in Turkey. Phytoparasitica 8(3): 243-244

Lietti M M M, Botto E \& Alzogaray R A (2005). Insecticide resistance in argentine populations of Tuta absoluta (Meyrick) (Lepidoptera: Gelechiidae). Neotropical Entomology 34(1): 113-119

Meyer J S, Ingersoll C G, Mc Donald L L \& Boyce M S (1986). Estimating Uncertainty in population growth rates: jacknife vs. bootstrap techniques. Ecology 67: 1156-1166

Miranda M M M, Picanco M, Zanuncio J C \& Guderes R N C (1998). Ecological life table of Tuta absoluta (Meyrick) (Lepidoptera: Gelechiidae). Biocontrol Sciences Technology 8: 597-606

Pereyra P C \& Sanchez N E (2006). Effect of two solanaceous plants on developmental and population parameters of the tomato leaf miner, Tuta absoluta (Meyrick) (Lepidoptera:Gelechiidae). Neotropical Entomology 35: 671-676

Sokal R R \& Rohlf F J (1995). Biometry. Third edition. Freeman and Co., New York

Torres J B, Faria C A, Evangelista W S \& Pratissoli D (2001). Within plant distribution of leaf miner Tuta absoluta (Meyrick) immatures in processing tomatoes, with notes on plant phenology. International Journal of Pest Management 47(3): 173-178

Watson T F (1964). Influence of host plant condition on population increase of Tetranychus telarius (L.) (Acarina: Tetranychidae). Hilgardia 35: 273-322 